\title{
NEW INEQUALITIES OF OSTROWSKI TYPE FOR TWICE DIFFERENTIABLE MAPPINGS
}

\author{
B. G. PACHPATTE
}

\begin{abstract}
In this paper, using integral identities for twice differentiable mappings, we establish new inequalities which in the special cases yield certain Ostrowski type inequalities recently established in the literature.
\end{abstract}

\section{Introduction}

In [1] Cerone, Dragomir and Roumeliotis proved the following identity:

$$
\int_{a}^{b} f(t) d t=(b-a) f(x)-(b-a)\left(x-\frac{a+b}{2}\right) f^{\prime}(x)+\int_{a}^{b} k(x, t) f^{\prime \prime}(t) d t,
$$

for $x \in[a, b]$, where $f:[a, b] \rightarrow R$ is a twice differentiable mapping on $(a, b)$ and $k(x, t):[a, b]^{2} \rightarrow R$ is given by

$$
k(x, t)=\left\{\begin{array}{ll}
\frac{(t-a)^{2}}{2} & \text { if } t \in[a, x] \\
\frac{(t-b)^{2}}{2} & \text { if } t \in(x, b]
\end{array} .\right.
$$

In another paper [2] Dragomir and Barnett have proved the following identity:

$$
\begin{aligned}
f(x)= & \frac{1}{b-a} \int_{a}^{b} f(t) d t+\frac{f(b)-f(a)}{b-a}\left(x-\frac{a+b}{2}\right) \\
& +\frac{1}{(b-a)^{2}} \int_{a}^{b} \int_{a}^{b} p(x, t) p(t, s) f^{\prime \prime}(s) d s d t,
\end{aligned}
$$

for $x \in[a, b]$, where $f:[a, b] \rightarrow R$ is continuous on $[a, b]$ and twice differentiable on $(a, b)$ and $p(x, t):[a, b]^{2} \rightarrow R$ is given by

$$
p(x, t)=\left\{\begin{array}{ll}
t-a & \text { if } t \in[a, x] \\
t-b & \text { if } t \in(x, b]
\end{array} .\right.
$$

Received December 30, 2002; revised February 13, 2003.

2000 Mathematics Subject Classification. 26D15, 41A55.

Key words and phrases. Inequalities of Ostrowski type, differentiable mappings, properties of modulus, absolutely continuous. 
In the same papers [1] and [2] based on the identities (1.1) and (1.3), the authors have respectively established the following Ostrowski type inequalities:

$$
\left|f(x)-\frac{1}{b-a} \int_{a}^{b} f(t) d t-\left(x-\frac{a+b}{2}\right) f^{\prime}(x)\right| \leq E(x)\left\|f^{\prime \prime}\right\|_{\infty},
$$

for $x \in[a, b]$, where

$$
E(x)=\frac{1}{24}(b-a)^{2}+\frac{1}{2}\left(x-\frac{a+b}{2}\right)^{2}
$$

$f:[a, b] \rightarrow R$ is a twice differentiable mapping on $(a, b)$ and $f^{\prime \prime}:(a, b) \rightarrow R$ is bounded i.e. $\left\|f^{\prime \prime}\right\|_{\infty}=\sup _{t \in(a, b)}\left|f^{\prime \prime}(t)\right|<\infty$, and

$$
\left|f(x)-\frac{1}{b-a} \int_{a}^{b} f(t) d t-\frac{f(b)-f(a)}{b-a}\left(x-\frac{a+b}{2}\right)\right| \leq L(x)\left\|f^{\prime \prime}\right\|_{\infty},
$$

for $x \in[a, b]$, where

$$
L(x)=\frac{1}{2}\left\{\left[\frac{\left(x-\frac{a+b}{2}\right)^{2}}{(b-a)^{2}}+\frac{1}{4}\right]^{2}+\frac{1}{12}\right\}(b-a)^{2},
$$

$f:[a, b] \rightarrow R$ is continuous on $[a, b]$ and twice differentiable on $(a, b)$, whose second derivative $f^{\prime \prime}:(a, b) \rightarrow R$ is bounded on $(a, b)$.

For similar results, see the book [4] by Mitrinović, Pečarić and Fink and the recent papers $[5,6]$, where further references are given. The main purpose of the present paper is to establish new Ostrowski type inequalities involving a pair of twice differentiable mappings. The analysis used in the proofs is quite elementary and our results in the special cases recapture the inequalities (1.5) and (1.7).

\section{Statement of Results}

Our main results are given in the following theorems.

Theorem 1. Let $f, g:[a, b] \rightarrow R$ be twice differentiable mappings on $(a, b)$ and $f^{\prime \prime}, g^{\prime \prime}:(a, b) \rightarrow R$ are bounded i.e. $\left\|f^{\prime \prime}\right\|_{\infty}=\sup _{t \in(a, b)}\left|f^{\prime \prime}(t)\right|<\infty,\left\|g^{\prime \prime}\right\|_{\infty}=$ $\sup _{t \in(a, b)}\left|g^{\prime \prime}(t)\right|<\infty$. Then

$$
\begin{aligned}
& \mid 2\left(\frac{1}{b-a} \int_{a}^{b} f(t) d t\right)\left(\frac{1}{b-a} \int_{a}^{b} g(t) d t\right)-\left[f(x)-\left(x-\frac{a+b}{2}\right) f^{\prime}(x)\right]\left(\frac{1}{b-a} \int_{a}^{b} g(t) d t\right) \\
& -\left[g(x)-\left(x-\frac{a+b}{2}\right) g^{\prime}(x)\right]\left(\frac{1}{b-a} \int_{a}^{b} f(t) d t\right) \mid
\end{aligned}
$$




$$
\begin{aligned}
& \leq E(x)\left[\left\|f^{\prime \prime}\right\|_{\infty}\left(\frac{1}{b-a} \int_{a}^{b}|g(t)| d t\right)+\left\|g^{\prime \prime}\right\|_{\infty}\left(\frac{1}{b-a} \int_{a}^{b}|f(t)| d t\right)\right] \\
& \left|\left(\frac{1}{b-a} \int_{a}^{b} f(t) d t\right) g(x)+\left(\frac{1}{b-a} \int_{a}^{b} g(t) d t\right) f(x)+\left(x-\frac{a+b}{2}\right)(f g)^{\prime}(x)-2 f(x) g(x)\right| \\
& \leq E(x)\left[\left\|f^{\prime \prime}\right\|_{\infty}|g(x)|+\left\|g^{\prime \prime}\right\|_{\infty}|f(x)|\right],
\end{aligned}
$$

for $x \in[a, b]$, where $E(x)$ is given by (1.6).

Theorem 2. Let $f, g:[a, b] \rightarrow R$ are continuous on $[a, b]$ and twice differentiable on $(a, b)$, whose second derivatives $f^{\prime \prime}, g^{\prime \prime}:(a, b) \rightarrow R$ are bounded on $(a, b)$ i.e. $\left\|f^{\prime \prime}\right\|_{\infty}=$ $\sup _{t \in(a, b)}\left|f^{\prime \prime}(t)\right|<\infty,\left\|g^{\prime \prime}\right\|_{\infty}=\sup _{t \in(a, b)}\left|g^{\prime \prime}(t)\right|<\infty$. Then

$$
\begin{aligned}
& \mid f(x)\left(\frac{1}{b-a} \int_{a}^{b} g(t) d t\right)+g(x)\left(\frac{1}{b-a} \int_{a}^{b} f(t) d t\right)-2\left(\frac{1}{b-a} \int_{a}^{b} f(t) d t\right)\left(\frac{1}{b-a} \int_{a}^{b} g(t) d t\right) \\
&- {\left[\frac{f(b)-f(a)}{b-a}\left(x-\frac{a+b}{2}\right)\left(\frac{1}{b-a} \int_{a}^{b} g(t) d t\right)\right.} \\
&\left.+\frac{g(b)-g(a)}{b-a}\left(x-\frac{a+b}{2}\right)\left(\frac{1}{b-a} \int_{a}^{b} f(t) d t\right)\right] \mid \\
& \leq L(x) {\left[\left\|f^{\prime \prime}\right\|_{\infty}\left(\frac{1}{b-a} \int_{a}^{b}|g(t)| d t\right)+\left\|g^{\prime \prime}\right\|_{\infty}\left(\frac{1}{b-a} \int_{a}^{b}|f(t)| d t\right)\right], } \\
& \mid 2 f(x) g(x)-\left\{\left[\frac{1}{b-a} \int_{a}^{b} f(t) d t+\frac{f(b)-f(a)}{b-a}\left(x-\frac{a+b}{2}\right)\right] g(x)\right.\left.+\left[\frac{1}{b-a} \int_{a}^{b} g(t) d t+\frac{g(b)-g(a)}{b-a}\left(x-\frac{a+b}{2}\right)\right] f(x)\right\} \mid \\
& \leq L(x)\left[\left\|f^{\prime \prime}\right\|_{\infty}|g(x)|+\left\|g^{\prime \prime}\right\|_{\infty}|f(x)|\right],
\end{aligned}
$$

for $x \in[a, b]$, where $L(x)$ is given by (1.8).

Remark 1. It is easy to observe that, by taking $g(x)=1$ and hence $g^{\prime}(x)=0$, $g^{\prime \prime}(x)=0$ in Theorems 1 and 2, we recapture respectively the inequalities (1.5) and (1.7) given in [1] and [2].

\section{Proof of Theorem 1}

From the hypotheses, we have the following identities (see [1, pp.34-35]):

$$
\frac{1}{b-a} \int_{a}^{b} f(t) d t=\left[f(x)-\left(x-\frac{a+b}{2}\right) f^{\prime}(x)\right]+\frac{1}{b-a} \int_{a}^{b} k(x, t) f^{\prime \prime}(t) d t,
$$




$$
\frac{1}{b-a} \int_{a}^{b} g(t) d t=\left[g(x)-\left(x-\frac{a+b}{2}\right) g^{\prime}(x)\right]+\frac{1}{b-a} \int_{a}^{b} k(x, t) g^{\prime \prime}(t) d t,
$$

for $x \in[a, b]$, where $k(x, t)$ is given by (1.2). Multiplying both (3.1) and (3.2) by $\frac{1}{b-a} \int_{a}^{b} g(t) d t$ and $\frac{1}{b-a} \int_{a}^{b} f(t) d t$ respectively, we get

$$
\begin{aligned}
& 2\left(\frac{1}{b-a} \int_{a}^{b} f(t) d t\right)\left(\frac{1}{b-a} \int_{a}^{b} g(t) d t\right) \\
= & {\left[f(x)-\left(x-\frac{a+b}{2}\right) f^{\prime}(x)\right]\left(\frac{1}{b-a} \int_{a}^{b} g(t) d t\right) } \\
& +\left[g(x)-\left(x-\frac{a+b}{2}\right) g^{\prime}(x)\right]\left(\frac{1}{b-a} \int_{a}^{b} f(t) d t\right) \\
& +\left(\frac{1}{b-a} \int_{a}^{b} k(x, t) f^{\prime \prime}(t) d t\right)\left(\frac{1}{b-a} \int_{a}^{b} g(t) d t\right) \\
& +\left(\frac{1}{b-a} \int_{a}^{b} k(x, t) g^{\prime \prime}(t) d t\right)\left(\frac{1}{b-a} \int_{a}^{b} f(t) d t\right),
\end{aligned}
$$

for $x \in[a, b]$. From (3.3) and using the properties of modulus we have

$$
\begin{aligned}
& \mid 2\left(\frac{1}{b-a} \int_{a}^{b} f(t) d t\right)\left(\frac{1}{b-a} \int_{a}^{b} g(t) d t\right)-\left[f(x)-\left(x-\frac{a+b}{2}\right) f^{\prime}(x)\right]\left(\frac{1}{b-a} \int_{a}^{b} g(t) d t\right) \\
& \quad-\left[g(x)-\left(x-\frac{a+b}{2}\right) g^{\prime}(x)\right]\left(\frac{1}{b-a} \int_{a}^{b} f(t) d t\right) \mid \\
& \leq\left[\left\|f^{\prime \prime}\right\|_{\infty}\left(\frac{1}{b-a} \int_{a}^{b}|g(t)| d t\right)+\left\|g^{\prime \prime}\right\|_{\infty}\left(\frac{1}{b-a} \int_{a}^{b}|f(t)| d t\right)\right]\left(\frac{1}{b-a} \int_{a}^{b}|k(x, t)| d t\right) .
\end{aligned}
$$

In fact, from (1.2) and using the elementary calculations as in [1, p.35] we obtain

$$
\frac{1}{b-a} \int_{a}^{b}|k(x, t)| d t=E(x), \quad x \in[a, b] .
$$

Using (3.5) in (3.4) we get the required inequality in (2.1).

Rewriting (3.1) and (3.2) as

$$
\begin{aligned}
& f(x)=\frac{1}{b-a} \int_{a}^{b} f(t) d t+\left(x-\frac{a+b}{2}\right) f^{\prime}(x)-\frac{1}{b-a} \int_{a}^{b} k(x, t) f^{\prime \prime}(t) d t, \\
& g(x)=\frac{1}{b-a} \int_{a}^{b} g(t) d t+\left(x-\frac{a+b}{2}\right) g^{\prime}(x)-\frac{1}{b-a} \int_{a}^{b} k(x, t) g^{\prime \prime}(t) d t,
\end{aligned}
$$

Multiplying both sides of $(3.1)^{\prime}$ and $(3.2)^{\prime}$ by $g(x)$ and $f(x)$ respectively and adding, we get

$$
2 f(x) g(x)=\left(\frac{1}{b-a} \int_{a}^{b} f(t) d t\right) g(x)+\left(\frac{1}{b-a} \int_{a}^{b} g(t) d t\right) f(x)+\left(x-\frac{a+b}{2}\right)(f g)^{\prime}(x)
$$




$$
-\left(\frac{1}{b-a} \int_{a}^{b} k(x, t) f^{\prime \prime}(t) d t\right) g(x)-\left(\frac{1}{b-a} \int_{a}^{b} k(x, t) g^{\prime \prime}(t) d t\right) f(x) .
$$

Rewriting (3.6) and using the properties of modulus and (3.5) we get the desired inequality in $(2.2)$.

\section{Proof of Theorem 2}

From the hypotheses, we have the following identities (see [2, pp.70-71]):

$$
\begin{aligned}
f(x)= & \frac{1}{b-a} \int_{a}^{b} f(t) d t+\frac{f(b)-f(a)}{b-a}\left(x-\frac{a+b}{2}\right) \\
& +\frac{1}{(b-a)^{2}} \int_{a}^{b} \int_{a}^{b} p(x, t) p(t, s) f^{\prime \prime}(s) d s d t, \\
g(x)= & \frac{1}{b-a} \int_{a}^{b} g(t) d t+\frac{g(b)-g(a)}{b-a}\left(x-\frac{a+b}{2}\right) \\
& +\frac{1}{(b-a)^{2}} \int_{a}^{b} \int_{a}^{b} p(x, t) p(t, s) g^{\prime \prime}(s) d s d t,
\end{aligned}
$$

for $x \in[a, b]$, where $p(x, t)$ is given by (1.4). Multiplying both sides of (4.1) and (4.2) by $\frac{1}{b-a} \int_{a}^{b} g(t) d t$ and $\frac{1}{b-a} \int_{a}^{b} f(t) d t$ respectively and adding, we get

$$
\begin{aligned}
& f(x)\left(\frac{1}{b-a} \int_{a}^{b} g(t) d t\right)+g(x)\left(\frac{1}{b-a} \int_{a}^{b} f(t) d t\right) \\
= & 2\left(\frac{1}{b-a} \int_{a}^{b} f(t) d t\right)\left(\frac{1}{b-a} \int_{a}^{b} g(t) d t\right) \\
& +\frac{f(b)-f(a)}{b-a}\left(x-\frac{a+b}{2}\right)\left(\frac{1}{b-a} \int_{a}^{b} g(t) d t\right) \\
& +\frac{g(b)-g(a)}{b-a}\left(x-\frac{a+b}{2}\right)\left(\frac{1}{b-a} \int_{a}^{b} f(t) d t\right) \\
& +\left(\frac{1}{(b-a)^{2}} \int_{a}^{b} \int_{a}^{b} p(x, t) p(t, s) f^{\prime \prime}(s) d s d t\right)\left(\frac{1}{b-a} \int_{a}^{b} g(t) d t\right) \\
& +\left(\frac{1}{(b-a)^{2}} \int_{a}^{b} \int_{a}^{b} p(x, t) p(t, s) g^{\prime \prime}(s) d s d t\right)\left(\frac{1}{b-a} \int_{a}^{b} f(t) d t\right)
\end{aligned}
$$

for $x \in[a, b]$. From (4.3) and using the properties of modulus we have

$$
\begin{aligned}
& f(x)\left(\frac{1}{b-a} \int_{a}^{b} g(t) d t\right)+g(x)\left(\frac{1}{b-a} \int_{a}^{b} f(t) d t\right)-2\left(\frac{1}{b-a} \int_{a}^{b} f(t) d t\right)\left(\frac{1}{b-a} \int_{a}^{b} g(t) d t\right) \\
& -\frac{f(b)-f(a)}{b-a}\left(x-\frac{a+b}{2}\right)\left(\frac{1}{b-a} \int_{a}^{b} g(t) d t\right)
\end{aligned}
$$




$$
\begin{aligned}
& -\frac{g(b)-g(a)}{b-a}\left(x-\frac{a+b}{2}\right)\left(\frac{1}{b-a} \int_{a}^{b} f(t) d t\right) \mid \\
\leq & {\left[\left\|f^{\prime \prime}\right\|_{\infty}\left(\frac{1}{b-a} \int_{a}^{b}|g(t)| d t\right)+\left\|g^{\prime \prime}\right\|_{\infty}\left(\frac{1}{b-a} \int_{a}^{b}|f(t)| d t\right)\right] } \\
\times & \left(\frac{1}{(b-a)^{2}} \int_{a}^{b} \int_{a}^{b}|p(x, t)||p(t, s)| d s d t\right) .
\end{aligned}
$$

In [2, pp.71-74] by using (1.4) and simple algebraic manipulations the authors have obtain

$$
\frac{1}{(b-a)^{2}} \int_{a}^{b} \int_{a}^{b}|p(x, t)||p(t, s)| d s d t=L(x),
$$

for $x \in[a, b]$. Using (4.5) in (4.4), we get the inequality in (2.3).

To prove the inequality (2.4), we multiply both sides of (4.1) and (4.2) by $g(x)$ and $f(x)$ respectively and add them to get

$$
\begin{aligned}
2 f(x) g(x)= & {\left[\frac{1}{b-a} \int_{a}^{b} f(t) d t+\frac{f(b)-f(a)}{b-a}\left(x-\frac{a+b}{2}\right)\right] g(x) } \\
& +\left[\frac{1}{b-a} \int_{a}^{b} g(t) d t+\frac{g(b)-g(a)}{b-a}\left(x-\frac{a+b}{2}\right)\right] f(x) \\
& +\left(\frac{1}{(b-a)^{2}} \int_{a}^{b} \int_{a}^{b} p(x, t) p(t, s) f^{\prime \prime}(s) d s d t\right) g(x) \\
& +\left(\frac{1}{(b-a)^{2}} \int_{a}^{b} \int_{a}^{b} p(x, t) p(t, s) g^{\prime \prime}(s) d s d t\right) f(x) .
\end{aligned}
$$

Rewriting (4.6) and using the properties of modulus and (4.5) we get the required inequality in (2.4).

\section{Further Inequalities}

In this section, we establish further inequalities of the type given in Theorems 1 and 2 based on the identity proved by Dragomir and Sofo in [3].

Theorem 3. Let $f, g:[a, b] \rightarrow R$ be mappings whose first derivatives are absolutely continuous on $[a, b]$ and assume that the second derivatives $f^{\prime \prime}, g^{\prime \prime} \in L_{\infty}[a, b]$. Then

$$
\begin{aligned}
& \mid 2\left(\frac{1}{b-a} \int_{a}^{b} f(t) d t\right)\left(\frac{1}{b-a} \int_{a}^{b} g(t) d t\right) \\
& \quad-\left\{\frac{1}{2}\left[f(x)+\frac{f(a)+f(b)}{2}\right]-\left(x-\frac{a+b}{2}\right) f^{\prime}(x)\right\}\left(\frac{1}{b-a} \int_{a}^{b} g(t) d t\right)
\end{aligned}
$$




$$
\begin{aligned}
& \quad-\left\{\frac{1}{2}\left[g(x)+\frac{g(a)+g(b)}{2}\right]-\left(x-\frac{a+b}{2}\right) g^{\prime}(x)\right\}\left(\frac{1}{b-a} \int_{a}^{b} f(t) d t\right) \mid \\
& \leq M(x)\left[\left\|f^{\prime \prime}\right\|_{\infty}\left(\frac{1}{b-a} \int_{a}^{b}|g(t)| d t\right)+\left\|g^{\prime \prime}\right\|_{\infty}\left(\frac{1}{b-a} \int_{a}^{b}|f(t)| d t\right)\right], \\
& \mid\left(\frac{1}{b-a} \int_{a}^{b} f(t) d t\right) g(x)+\left(\frac{1}{b-a} \int_{a}^{b} g(t) d t\right) f(x)-f(x) g(x) \\
& -\frac{1}{2}\left[\frac{f(a)+f(b)}{2} g(x)+\frac{g(a)+g(b)}{2} f(x)\right]-\left(x-\frac{a+b}{2}\right)(f g)^{\prime}(x) \mid \\
& \leq M(x)\left[\left\|f^{\prime \prime}\right\|_{\infty}|g(x)|+\left\|g^{\prime \prime}\right\|_{\infty}|f(x)|\right],
\end{aligned}
$$

for $x \in[a, b]$, where

$$
M(x)=\frac{1}{2(b-a)} \int_{a}^{b}|p(x, t)|\left|t-\frac{a+b}{2}\right| d t .
$$

From the hypotheses, we have the following identities (see [3, pp.231-232]):

$$
\begin{aligned}
\frac{1}{b-a} \int_{a}^{b} f(t) d t= & \frac{1}{2}\left[f(x)+\frac{f(a)+f(b)}{2}\right]-\left(x-\frac{a+b}{2}\right) f^{\prime}(x) \\
& +\frac{1}{2(b-a)} \int_{a}^{b} p(x, t)\left(t-\frac{a+b}{2}\right) f^{\prime \prime}(t) d t \\
\frac{1}{b-a} \int_{a}^{b} g(t) d t= & \frac{1}{2}\left[g(x)+\frac{g(a)+g(b)}{2}\right]-\left(x-\frac{a+b}{2}\right) g^{\prime}(x) \\
& +\frac{1}{2(b-a)} \int_{a}^{b} p(x, t)\left(t-\frac{a+b}{2}\right) g^{\prime \prime}(t) d t,
\end{aligned}
$$

for $x \in[a, b]$. Multiplying (5.4) and (5.5) respectively by $\frac{1}{b-a} \int_{a}^{b} g(t) d t$ and $\frac{1}{b-a} \int_{a}^{b} f(t) d t$, adding and following the proof of inequality (2.1) (or (2.3)) we get the inequality (5.1).

Multiplying both sides of (5.4) and (5.5) respectively by $g(x)$ and $f(x)$, adding the resulting identities and following the proof of inequality (2.2) (or (2.4)) we get the desired inequality in (5.2).

Remark 2. We note that in [3, pp.232-234] the authors have evaluated the integral in (5.3) and obtain

$$
M(x)=\frac{1}{3(b-a)}\left|x-\frac{a+b}{2}\right|^{3}+\frac{(b-a)^{2}}{48},
$$

for $x \in[a, b]$. If we take $g(x)=1$ and hence $g^{\prime}(x)=0, g^{\prime \prime}(x)=0$, in Theorem 3 , then we get the inequality established by Dragomir and Sofo in $[3, \mathrm{p} .230]$. 


\section{References}

[1] P. Cerone, S. S. Dragomir and J. Roumeliotis, An inequality of Ostrowski type for mappings whose second derivatives are bounded and applications, RGMIA Research Report Collection 1(1998), 33-39.

[2] S. S. Dragomir and N. S. Barnett, An Ostrowski type inequality for mappings whose second derivatives are bounded and applications, RGMIA Research Report Collection 1(1998), 6977 .

[3] S. S. Dragomir and A. Sofo, An integral inequality for twice differentiable mappings and applications, RGMIA Research Report Collection 2(1999), 229-240.

[4] D. S. Mitrinović, J. E. Pečarić and A. M. Fink, Inequalities for Functions and Their Integrals and Derivatives, Kluwer Academic Publishers, Dordrecht, 1994.

[5] B. G. Pachpatte, On Grüss type integral inequalities, J. Inequal. Pure and Appl. Math. 3(2002), Art.11.

[6] B. G. Pachpatte, On multivariate Ostrowski type inequalities, J. Inequal. Pure and Appl. Math. 3(2002), Art.58.

57 Shri Niketan Colony, Near Abhinay Talkies, Aurangabad 431 004, (Maharashtra), India. 